\title{
Early Electrodiagnostic Findings of Guillain Barre Syndrome
}

\section{Sharma Geetanjali ${ }^{1 *}$, Sood Sushma ${ }^{1}$ and Sharma Sudhir ${ }^{2}$}

${ }^{1}$ Department of Physiology, University of Health Sciences, Haryana, India

${ }^{2}$ Department of Medicine, University of Health Sciences, Haryana, India

\begin{abstract}
Purpose: Guillain Barre Syndrome (GBS) is an acute immune mediated de-mylelinating poly-radiculoneuropathy. As early diagnosis favors a good outcome after treatment, this study was carried out to analyze the electro-physiological abnormalities in the first week of GBS in this region.

Basic procedures: The study was carried out for early confirmation of GBS in 65 clinically diagnosed patients reporting within a week of muscle weakness by electro-physiological tests in the years 2010-12.

Results: Slowing of motor conduction velocities, decreased amplitude and increased distal motor latencies (DML) was seen in peroneal, tibial, median and ulnar nerves in descending order of severity. Conduction block was seen in the lower limb in $10(15.38 \%)$ patients. F-wave was completely absent in upper and lower limbs in 50 $(76.92 \%)$ patients while 15 patients $(23.07 \%)$ showed decreased F-wave conduction velocity in both limbs. Sensory conduction velocity of median nerve was less compared to sural. EMG studies showed that demyelinating type of neuropathy was predominant $(83.33 \%)$.

Discussion: Electro-physiological studies play an important role in the early detection; characterization \& treatment of GBS because timely intervention reduces morbidity and disability. Increased DML, absent F- wave, decreased median with normal Sural SCV (sensory conduction velocity) is diagnostic of early GBS.
\end{abstract}

Keywords: Peripheral neuropathic weakness; Electro-diagnosis; Early signs

\section{Introduction}

GBS is an auto-immune mediated de-myelinating polyradiculoneuropathy. Males \& females are equally at risk. Clinical features include progressive, symmetrical ascending muscle weakness of more than two limbs, areflexia with or without sensory, autonomic and brainstem abnormalities (Table 1). Weakness is prominent in leg muscles as compared to arms; there is absence of fever at the onset of neural symptoms. Cranial nerve involvement may affect airway and facial muscles, eye movements and swallowing [1]. It usually presents with numbness and tingling in the feet [2].

In 1949, Haymaker and Kernohan reported the histo-pathological features of 50 fatal cases of GBS. The earliest features were edema of proximal nerves followed by degeneration of myelin sheath within the 1st week of illness [3].

Electro-diagnosis plays an important role in early detection and characterization of inflammatory de-myelinating polyradiculopathies [4].

Nerve conduction abnormalities become more prominent during the initial weeks of the disease even if patients clinical status is improving [5,6]. Early nerve conduction findings include abnormal or absent $\mathrm{F}$ waves with low CNAP's, an abnormal upper extremity sensory nerve action potential combined with normal sural response and multiple indirect discharges $[4,7,8]$.

\section{Material and Methods}

Ethics committee approval: There was no issue of ethical committee approval during this study as the patients were referred from department of Medicine of our Institute for electro-diagnostic evaluation (Table 2).

The present study was carried out to facilitate early confirmation of clinically diagnosed cases of GBS in the 1st week of illness that were sent to the Department of Physiology for nerve conduction. The study was conducted on these 65 subjects ( 42 males \& 23 females) between the age group of 6-70 years using RMS EMG EP Mark-II Chandigarh. The criteria for clinical diagnosis of GBS were rapidly progressive limb weakness with or without distal limb paresthesias and reduced deep tendon reflexes.

The parameters considered were divided into four major groups-

1. Motor conduction studies included: Median, ulnar, tibial and peroneal conduction velocities, amplitude and their distal motor latencies.

2. Sensory conduction studies included: Medial and sural nerve conduction velocities.

3. $\mathrm{F}$ wave studies: $\mathrm{F}$ wave studies included $\mathrm{F}$ wave conduction velocity \& F wave latency. (F wave is a late response resulting from antidromic activation of motor neurons involving conduction to and from spinal cord. F wave studies have been established as a valuable tool in clinical neuro-physiology [9]. Prominent slowing of $\mathrm{F}$ waves has been reported in GBS where the demyelination may affect the proximal segment of nerve and even the roots which cannot be assessed by routine nerve conduction studies [10].

*Corresponding author: Geetanjali Sharma, Department of Physiology, University of Health Sciences, Haryana, India; Tel: 91126221316; E-mail: drgeeta1212@yahoo.com

Received November 28, 2012; Accepted December 29, 2012; Published January 15,2013

Citation: Geetanjali S, Sushma S, Sudhir S (2013) Early Electrodiagnostic Findings of Guillain Barre Syndrome. J Neurol Neurophysiol 4: 142. doi:10.4172/2155 9562.1000142

Copyright: (c) 2013 Geetanjali S, et al. This is an open-access article distributed under the terms of the Creative Commons Attribution License, which permits unrestricted use, distribution, and reproduction in any medium, provided the original author and source are credited. 
Citation: Geetanjali S, Sushma S, Sudhir S (2013) Early Electrodiagnostic Findings of Guillain Barre Syndrome. J Neurol Neurophysiol 4: 142. doi:10.4172/2155-9562.1000142

\begin{tabular}{|c|c|}
\hline Variables & No. of patients \\
\hline Males/females & $42 / 23$ \\
\hline Age range & $6-70$ \\
\hline Age<60 & 59 \\
\hline Weakness & $65 / 65$ \\
\hline Areflexia & $58 / 65$ \\
\hline
\end{tabular}

Table 1: Clinical features in 65 patients of GBS.

\begin{tabular}{|c|c|c|}
\hline \multirow{2}{*}{\multicolumn{2}{|c|}{\begin{tabular}{|l|} 
Variable \\
1. $F$ waves Abnormal, total
\end{tabular}}} & \multirow[t]{2}{*}{ No $(\%)$ of patients } \\
\hline & & \\
\hline \multirow{3}{*}{ a. Upper limb } & Absent & $50(76.92 \%)$ \\
\hline & Prolonged latency & $15(23.07 \%)$ \\
\hline & Normal & 0 \\
\hline \multirow{3}{*}{ b. Lower limb } & Absent & $50(76.92 \%)$ \\
\hline & Prolonged latency & $15(23.07 \%)$ \\
\hline & Normal & 0 \\
\hline \multicolumn{3}{|l|}{ 2. SCV } \\
\hline \multirow{3}{*}{ a. Upper limb } & Normal & $55(84.61 \%)$ \\
\hline & Decrease & $05(7.69 \%)$ \\
\hline & Absent & $05(7.69 \%)$ \\
\hline \multirow{3}{*}{ b. Lower Limb (Sural) } & Normal & $40(61.29 \%)$ \\
\hline & Decrease & $20(30.76 \%)$ \\
\hline & Absent & $5(7.69 \%)$ \\
\hline \multicolumn{3}{|c|}{ 3. CMAP (compound muscle action potential) } \\
\hline \multicolumn{3}{|c|}{$\begin{array}{l}\text { A.Conduction velocity } \\
\text { (CV) \& amplitude }\end{array}$} \\
\hline \multirow{3}{*}{ a. Upper limb } & $\begin{array}{l}\text { Decrease in both Ulnar \& } \\
\text { median nerves }\end{array}$ & $44(67.6 \%)$ \\
\hline & Decrease in only ulnar nerve & $8(12.3 \%)$ \\
\hline & Normal CV & $13(20.1 \%)$ \\
\hline \multirow[t]{2}{*}{ b. Lower limb } & $\begin{array}{c}\text { Decrease in both tibial \& } \\
\text { peroneal nerves } \\
\text { Decrease in only tibial nerve }\end{array}$ & $\begin{array}{c}50(76.92 \%) \\
5(7.69 \%)\end{array}$ \\
\hline & Conduction block & $10(15.38 \%)$ \\
\hline \multicolumn{3}{|l|}{ B. Distal motor latency } \\
\hline \multirow[t]{2}{*}{ a. Upper limb } & $\begin{array}{l}\text { Increase in both Ulnar \& } \\
\text { median nerves }\end{array}$ & $42(64 \%)$ \\
\hline & Increase in only ulnar nerve & $8(12 \%)$ \\
\hline \multirow{3}{*}{ b. Lower limb } & \begin{tabular}{|c|}
$\begin{array}{c}\text { Increase in both tibial \& } \\
\text { peroneal nerves }\end{array}$ \\
\end{tabular} & $50(76.92 \%)$ \\
\hline & $\begin{array}{l}\text { Increase in only tibial } \\
\text { nerve }\end{array}$ & $5(7.69 \%)$ \\
\hline & Conduction block & $10(15.38 \%)$ \\
\hline \multirow{2}{*}{ 4. EMG } & Demyelinating type & $60(92.30 \%)$ \\
\hline & Axonal type & $5(7.69 \%)$ \\
\hline
\end{tabular}

Table 2: Electro-diagnostic findings in patients with Guillain Barre Syndrome within 1 week

4. EMG studies (Electro-myographic studies): Conducted in Deltoid \& Abductor digiti minimii (Upper Limb) and Tibialis anterior \& Peroneus longus muscles (lower limb).

\section{Electro-diagnostic criteria}

According to Dutch Guillain Barre study group criteria only one of the following abnormalities in at least two nerves should be considered [11].

1. Increased distal motor latency $>150 \%$ of upper limit of normal

2. Decreased conduction velocity $<70 \%$ of lower limit of normal

3. Increased $F$ wave latency $>150$ of upper limit of normal
4. Decreased compound muscle action potential amplitude>upper limit of normal.

The placement of electrodes was done on the basis of the technique described by Mishra and Kalita [12].

\section{Results}

\section{Distal motor latency}

Increased distal motor latency (DML) was seen in 42 (64\%) patients for both ulnar \& median nerves and exclusively for ulnar nerve in 8 (12\%) patients. 15 (23.07\%) patients had normal DML. On the case of the lower limbs, increased distal motor latency was seen in $50(76.92 \%)$ patients for both tibial \& peroneal nerves and exclusively for tibial nerve in $5(7.69 \%)$ patients.

\section{Conduction velocity and amplitude}

Decreased conduction velocity \& amplitude was seen in 44 (67.6\%) for both median \& ulnar nerves and exclusively for ulnar nerve in 8 (12.3\%) patients while $13(20.1 \%)$ patients had normal conduction velocities In lower limbs, decreased conduction velocity \& amplitude was seen in 50 (76.92\%) for both tibial \& peroneal nerves and exclusively for tibial nerve in $5(7.69 \%)$ patients. Conduction block was seen in the lower limb in $10(15.38 \%)$ patients.

So, slowing of motor conduction velocities, decreased amplitude as well as increase in distal motor latencies were observed, being more pronounced in the lower limbs.

\section{F-wave}

F-wave was completely absent in both upper and lower limbs in $50(76.92 \%)$ patients while 15 patients $(23.07 \%)$ showed decreased conduction velocity with prolonged latency and decreased amplitude in both upper and lower limbs.

\section{Sensory nerve action potential}

Decreased sensory conduction velocity (SCV) was seen in 40 (61.29\%), absent SCV in 20 (30.76\%) and normal SCV in 5 (7.69\%) patients in the upper limb. On the other hand, normal Sural nerve SCV [SSCV] was seen in 55 (84.61\%), decreased SSCV in 5 (7.69\%) and absent SSCV in 5 (7.69\%) patients in the lower limb.

So, sensory conduction velocity of median nerve was slightly less as compared to Sural nerve in lower limbs.

\section{EMG}

EMG studies were carried out in 30 of the 65 patients of the GBS group, of which $25(83.33 \%)$ showed demyelinating type of polyneuropathy with reduced voluntary motor unit recruitment while the remaining $5(16.66 \%)$ patients showed axonal type of polyneuropathy showing denervation pattern.

\section{Discussion}

Electro-diagnostic studies are helpful in diagnosis and differentiating demyelinating variety of GBS which responds to treatment and has a better prognosis [13]. Electro-physiological hallmarks of early demyelination include prolonged distal motor latencies, prolonged/absent $\mathrm{F}$ wave latencies mainly in the lower limbs, slow motor conduction velocities/conduction block with absent $\mathrm{F}$ wave, and abnormal upper extremity sensory nerve action potential as compared to the sural nerve. 
F wave is the most sensitive diagnostic test for early GBS. In our study, motor conduction velocity was decreased and proximal conduction block was noticed mainly in the lower limbs. The above results are in tandem with findings of Gordon, Jun Kimura and Kuwahara $[4,10,14]$. In a study done by Ropper et al. on 41 patients of GBS who underwent electro-diagnostic studies within a week of onset of symptoms, 16 patients had abnormalities of compound muscle action potentials including dispersion, delayed latency, low amplitude, conduction velocity slowing, conduction block or abnormal F-waves [15]. Similar results have been quoted by Clouston et al. [16].

Prolonged distal motor latencies \& prolonged or absent $\mathrm{F}$ waves reflect early predilection for involvement of proximal spinal roots and distal motor terminals. Upper limb SNAP's particularly of the median nerve can be affected more severely and earlier than those of the sural nerve. The explanation of this finding is multifactorial. Entrapment sites are more prone i.e. median nerve in Carpal Tunnel. Reduced SNAP amplitudes can be the result of secondary axonal degeneration and conduction block [17]. The conduction block was maximal in the terminal segment in the upper and lower limbs, more so in the lower limb. These findings were consistent with those of Brown [18]. $\mathrm{He}$ attributed being due to relative deficiency of the blood nerve barrier. Decrease in conduction velocity is damage to the myelin sheath; both cellular and immune mechanisms play important roles in it. Early inflammatory lesions consist of lymphocytic infiltrate; later on macrophages become prominent. The peripheral nerve changes consist of perivascular oedema, accumulation of mono-nuclear cells and paranodal \& less commonly segmental demyelination [19].

The EMG studies were conducted on 30 of the 65 patients because of proximity of electro-diagnosis to the symptom onset. EMG studies showed that demyelinating type of neuropathy was the predominant form of GBS (83.33\%) in our series. This was in consistence with the results of Yakoob et al. [20].

\section{Conclusion}

The global incidence of Guillain Barre Syndrome has been estimated between $1.1 / 100,000 /$ year to $1.8 / 100,000 /$ year [21]. Thus, this syndrome constitutes a major load of demyelinating polyneuropathy cases worldwide. There seems to be a slight preponderance of AIDP (acute inflammatory demyelinating polyneuropathy) variety in India as suggested by Gupta et al. and Meena et al. [22,23] AIDP was the preponderant variant in our study i.e. in the state of Haryana. The results were in line with the electro-diagnostic criteria for early diagnosis of GBS as described in literature. Electro-diagnostic techniques play an important role in the early detection and characterization of inflammatory demyelinating poly-radiculopathy in the first week of symptomology and assume importance in treatment of this syndrome because timely intervention reduces morbidity and disability.

\section{Acknowledgements}

The authors sincerely thank Mr. Randhir Singh, Senior Laboratory Technician, Department of Physiology, University of Health Sciences, for his untiring cooperation during nerve conduction studies of the patients.

\section{References}

1. Hauser SL, Asbury AK (2009) Guillain-Barre Syndrome \& other immunemediated neuropathies: 2667-2671.
2. Amato AA (2005) Guillain Barre syndrome \& related disorders. Rev Mex Neuroci 6: 455- 469 .

3. Haymaker W, Kernohan JW (1949) The Landry-Guillain-Barré syndrome; a clinicopathologic report of 50 fatal cases and a critique of the literature. Medicine (Baltimore) 28: 59-141.

4. Gordon PH, Wilbourn AJ (2001) Early electrodiagnostic findings in GuillainBarré syndrome. Arch Neurol 58: 913-917.

5. Albers JW (1989) AAEM Case report \#4- Guillain Barre Syndrome 12: 705-711.

6. McLeod JG (1995) Investigation of peripheral neuropathy. J Neurol Neurosurg Psychiatry 58: 274-283.

7. Roth G, Magistris MR (1999) Indirect discharges as an early nerve conduction abnormality in the Guillain-Barré syndrome. Eur Neurol 42: 83-89.

8. Aminoff MJ, Greenberg DA, Simon RP (2005) In Clinical Neurology. 6th ed McGraw-Hill Medical, New York.

9. Fisher MA (2002) $\mathrm{H}$ reflexes and $\mathrm{F}$ wave fundamentals normal and abnormal patterns. Neurol Clin N Am 20: 339.

10. Kimura J, Butzer JF (1975) F-wave conduction velocity in Guillain-Barré syndrome. Assessment of nerve segment between axilla and spinal cord. Arch Neurol 32: 524-529.

11. Meulstee J, Van Der Meche FG (1995) Electrodiagnostic criteria for polyneuropathy and demyelination: application in 135 patients with GuillainBarré syndrome. Dutch Guillain-Barré Study Group. J Neurol Neuro Surg Psychiat 59: 482-486.

12. Mishra VA, Kalita J (2006) Clinical Neurophysiology, (2ndedn). Elsevier Health Sciences, Gurgaon: 235.

13. Nadir ZK, Narullah M (1998) Electrodiagnostic study of 40 cases presenting as Guillain Barre Syndrome. Pak J Neurol 4: 50-54.

14. Kuwabara S, Ogawara K, Mizobuchi K, Koga M, Mori M, et al. (2000) Isolated absence of $\mathrm{F}$ waves and proximal axonal dysfunction in Guillain-Barré syndrome with antiganglioside antibodies. J Neurol Neurosurg Psychiatry 68 191-195.

15. Ropper AH, Wijdicks EF, Shahani BT (1990) Electrodiagnostic abnormalities in 113 consecutive patients with Guillain-Barré syndrome. Arch Neurol 47: 881 887

16. Clouston PD, Kiers L, Zuniga G, Cros D (1994) Quantitative analysis of the compound muscle action potential in early acute inflammatory demyelinating polyneuropathy. Electroencephalogr Clin Neurophysiol 93: 245-254.

17. Amato AA, Dumitru D (2002) Acquired neuropathies. In: Dumitru D, Amato AA Zwarts MJ. Editor. Electrodiagnostic medicine, (2ndedn). Philadelphia: Hanley \& Belfus, Inc: 937-1041.

18. Brown WF, Snow R (1991) Patterns and severity of conduction abnormalities in Guillain-Barré syndrome. J Neurol Neurosurg Psychiatry 54: 768-774.

19. Ramachandran TS, Lorenzo NY (2011) Acute Inflammatory Demyelinating Polyradiculoneuropathy.

20. Yakoob MY, Rahman A, Jamil B, Syed NA (2005) Characteristics of patients with Guillain Barre Syndrome at a tertiary care centre in Pakistan, 1995-2003. J Pak Med Assoc 55: 493-496.

21. McGrogan A, Madle GC, Seaman HE, de Vries CS (2009) The epidemiology of Guillain-Barré syndrome worldwide. A systematic literature review. Neuroepidemiology 32: 150-163.

22. Gupta D, Nair M, Baheti NN, Sarma PS, Kuruvilla A et al. (2008) DiplomateAmerican Board (2008) Electrodiagnostic and clinical aspects of Guillain-Barré syndrome: an analysis of 142 cases. J Clin Neuromuscul Dis 10: 42-51.

23. Meena AK, Khadilkar SV, Murthy JM (2011) Treatment guidelines for GuillainBarré Syndrome. Ann Indian Acad Neurol. 